\title{
A Fuzzy Control Chart Approach for Attributes and Variables
}

\author{
Nilufer Pekin Alakoc \\ College of Engineering and Technology \\ American University of The Middle East \\ Kuwait \\ Nilufer.Alakoc@aum.edu.kw
}

\author{
Aysen Apaydin \\ Department of Insurance and Actuary Sciences \\ Ankara University \\ Ankara, Turkey \\ aapaydin@ankara.edu.tr
}

\begin{abstract}
The purpose of this study is to present a new approach for fuzzy control charts. The procedure is based on the fundamentals of Shewhart control charts and the fuzzy theory. The proposed approach is developed in such a way that the approach can be applied in a wide variety of processes. The main characteristics of the proposed approach are: The type of the fuzzy control charts are not restricted for variables or attributes, and the approach can be easily modified for different processes and types of fuzzy numbers with the evaluation or judgment of decision maker(s). With the aim of presenting the approach procedure in details, the approach is designed for fuzzy c quality control chart and an example of the chart is explained. Moreover, the performance of the fuzzy $c$ chart is investigated and compared with the Shewhart $\mathrm{c}$ chart. The results of simulations show that the proposed approach has better performance and can detect the process shifts efficiently.
\end{abstract}

Keywords-component; fuzzy set theory; statistical process control; fuzzy control charts; average run length

\section{INTRODUCTION}

Recently, quality improvement has become the main interest of firms all over the world. There are several benefits of achieving better standards: increase in revenue, productivity, customer satisfaction and market share. Statistical methods such as design of experiments, hypotheses testing and statistical process control play an important role in quality improvement. The primary tool of statistical process control is quality control charts which were first introduced by Walter A. Shewhart [1]. A control chart provides information on changes of process mean and variance so that corrective actions can be undertaken as early as possible which leads to reduce variability, improve productivity and quality. On the other hand, statistical process control problems include uncertainty as most of the real world systems. If there is uncertainty in the process or if quality characteristics are described by human subjectivity, then the process cannot be defined accurately by Shewhart control charts. Therefore, fuzzy set theory is used to explain and model problems. The idea of fuzzy set theory was first introduced in [2], afterwards the theory was used in development of many procedures, approaches and fields to define and model systems. Applications of fuzzy theory on statistical process control have taken attention and been investigated widely which resulted in a new perspective in quality improvement. Many studies [3-10] were mainly focused on the adaptation of linguistic terms such as perfect, good, medium etc. to control charts. In [3, 4], authors proposed two fuzzy control chart approaches: probabilistic approach and membership approach. As an extension of these studies, a new approach for considering linguistic terms to express the process outcomes was introduced $[5,6]$. In another study on linguistic data [7], fuzzy control chart generation procedures were compared. In [8], authors studied on linguistic terms and suggested fuzzy approaches for attributes. Recently, an approach called transition probability approach based on Markov chain theory was developed [9].

Attribute control charts were discussed in $[10,11]$ and reviewed in [12]. A fuzzy approach for the determination of variable sampling interval was developed by a composition function [13]. In [14], authors suggested a fuzzy control chart based on fuzzy regression analysis with neural network and degree of fuzziness, and generated the fuzzy data by combining experts' opinion and measurements. In another study, direct fuzzy approach (DFA) was introduced for c control charts without using any defuzzification method [15]. Studies on fuzzy statistical quality control were reviewed in $[16,17]$ and the open fields and challenges for future work were discussed briefly. In [18-21], authors studied on fuzzy approaches for attributes control charts and emphasized the critical role of fuzzy data. A fuzzy $\mathrm{c}$ chart monitored with weighted possibilistic mean and weighted interval valued possibilistic mean of fuzzy numbers was introduced in [22]. There are many studies on monitoring variable control charts for uncertain observations. The former fuzzy control charting approach for variables is based on plotting control charts by considering uncertain process parameters for both variables and attributes [23]. In [24], authors developed a fuzzy chart with Pearson goodness of fit statistic which includes a warning line besides its upper control limit. Different procedures for variable control charts in which the Shewhart control limits are modified with uncertainty and randomness were proposed in [25-27]. Contributions to fuzzy process control works from a different point of view were also proposed, e.g. fuzzy EWMA, CUSUM control charts [28], adaptation of the run rules and recognition of the unnatural patterns of fuzzy control charts [29-31]. 
Authors in [32] investigated fuzzy multivariate control charts, in [33], nonparametric Shewhart control chart for fuzzy data, and control charts autocorrelated fuzzy observations in [34].

This paper introduces a new approach for constructing fuzzy control charts. The approach is proposed as an extension of Shewhart control charts and differs from the previous studies in flexible assumptions which do not restrict the type of the chart and application area. The charting procedure is based on membership degrees of fuzzy numbers, the pattern of $\alpha$-cut fuzzy numbers and fuzzy limits on the chart. The out of control condition is determined by a decision function which is developed by considering the distribution of membership degrees, the probability of type I error and $3 \sigma$ control limits. A simulation study is performed to demonstrate the performance of the approach.

\section{DESIGN OF FUZZY CONTROL CHART}

\section{A. The Procedure}

The approach is flexible and not restricted to a specified type of control chart, because any assumptions about the type of quality characteristic or the distribution of quality characteristic are not required. For this reason, the approach can be modified easily for control charts with different purposes. During the development process several different fuzzy control charts are plotted and different applications are examined. A sensitivity analysis is performed based on the applications and then effects of fuzzy numbers and parameters of membership function are investigated. If measurements and control limits of an approach are fuzzy numbers then the most essential part of constructing a fuzzy control chart is to define the intersection situations of fuzzy limits and numbers. If all the fuzzy numbers are between the fuzzy limits, then the process is in control and the membership degree of being in control is 1. Similarly, if any fuzzy number is completely out of the fuzzy control limits then the process is out of control and the membership degree is 0 . However, it is not easy to define the process if any fuzzy number intersects with the fuzzy control limits. The approach classifies these situations by a formula and assigns a membership degree to each fuzzy number in such a way that the importance of having a fuzzy number between the fuzzy limits, and the importance of intersecting with fuzzy limits are differentiated with the perspective of the decision maker. The proposed fuzzy control chart plots measurements of a quality characteristic in the form of $\alpha$-cut fuzzy numbers. The fuzzy control chart represents the fuzzy control limits and center line by two parallel lines which show upper and lower values of $\alpha$-cut fuzzy limits. $\alpha$-cut fuzzy numbers are illustrated with lines perpendicular to the limits.

Let $A_{i}$ is a trapezoidal fuzzy number, such that $A_{i}=$ $\left(a_{i}, b_{i}, c_{i}, d_{i}\right)$, then $\alpha$-cut trapezoidal fuzzy number is an interval in the form of $A_{i}^{\alpha}=\left[a_{i}+\alpha\left(b_{i}-a_{i}\right), d_{i}-\alpha\left(d_{i}-c_{i}\right),\right]=\left[a_{i}^{\alpha}, d_{i}^{\alpha}\right]$. If measurements are denoted by trapezoidal fuzzy numbers, then fuzzy control limits, $L \widetilde{C L}$ and $\widetilde{U C L}$, and the fuzzy center line, $\widetilde{C L}$ of fuzzy $\bar{x}$ and $R$ charts are defined as:

$$
\widetilde{L C} L_{\bar{x}}=\left(\bar{a}-A_{2} \bar{R}_{d}, \bar{b}-A_{2} \bar{R}_{c}, \bar{c}-A_{2} \bar{R}_{c}, \bar{d}-A_{2} \bar{R}_{a}\right)
$$

$$
\begin{gathered}
\widetilde{C L}_{\bar{x}}=(\bar{a}, \bar{b}, \bar{c}, \bar{d}) \\
\widetilde{U C L}_{\bar{x}}=\left(\bar{a}-A_{2} \bar{R}_{a}, \bar{b}+A_{2} \bar{R}_{b}, \bar{c}+A_{2} \bar{R}_{c}, \bar{d}+A_{2} \bar{R}_{d}\right) \\
\widetilde{L C}_{R}=\left(D_{3} \bar{R}_{a}, D_{3} \bar{R}_{b}, D_{3} \bar{R}_{c}, D_{3} \bar{R}_{d}\right) \\
\widetilde{C L}_{R}=\left(\bar{R}_{a}, \bar{R}_{b}, \bar{R}_{c}, \bar{R}_{d}\right) \\
\widetilde{U C L}_{R}=\left(D_{4} \bar{R}_{a}, D_{4} \bar{R}_{b}, D_{4} \bar{R}_{c}, D_{4} \bar{R}_{d}\right)
\end{gathered}
$$

where $\bar{R}_{t}=\sum R_{i_{t}} / m, \quad R_{i_{t}}=\max _{j \neq k}\left(t_{i j}-t_{i k}\right) \quad$ and $t=a, b, c, d$, $i=1, \ldots, m$. Similarly, fuzzy control limits and the center line of fuzzy $c$ control chart are calculated by:

$$
\begin{gathered}
L \widetilde{C L}=(\bar{a}-3 \sqrt{\bar{d}}, \bar{b}-3 \sqrt{\bar{c}}, \bar{c}-3 \sqrt{\bar{b}}, \bar{d}-3 \sqrt{\bar{a}}) \\
\widetilde{C L}=(\bar{a}, \bar{b}, \bar{c}, \bar{d}) \\
\widetilde{U C L}=(\bar{a}+3 \sqrt{\bar{a}}, \bar{b}+3 \sqrt{\bar{b}}, \bar{c}+3 \sqrt{\bar{c}}, \bar{d}+3 \sqrt{\bar{d}})
\end{gathered}
$$

Triangular fuzzy numbers are special cases of trapezoidal fuzzy numbers. Trapezoidal fuzzy numbers are reduced to triangular fuzzy numbers when $b=c$,. Let $B_{i}$ is a triangular fuzzy number, denoted by $B_{i}=\left(a_{i}, b_{i}, c_{i}\right)$, then $\alpha$-cut triangular fuzzy number is an interval such that $B_{i}^{\alpha}=\left[a_{i}^{\alpha}, c_{i}^{\alpha}\right]$. So that the fuzzy control limits of c chart, $L \widetilde{C L}$ and $\widetilde{U C L}$, are triangular fuzzy numbers:

$$
\begin{gathered}
L \widetilde{C L}=(\bar{a}-3 \sqrt{\bar{c}}, \bar{b}-3 \sqrt{\bar{b}}, \bar{c}-3 \sqrt{\bar{a}}) \\
\widetilde{C L}=(\bar{a}, \bar{b}, \bar{c}) \\
\widetilde{U C L}=(\bar{a}+3 \sqrt{a}, \bar{b}+3 \sqrt{\bar{b}}, \bar{c}+3 \sqrt{\bar{c}})
\end{gathered}
$$

The approach is not limited to any specified type of fuzzy numbers, but for the simplicity, the procedure is explained by triangular fuzzy numbers. If $v_{i}^{\alpha}$ is the $\alpha$-cut range of $i^{\text {th }}$ fuzzy number, then this range is defined as:

$$
v_{i}^{\alpha}=v_{i, \text { in }}^{\alpha}+v_{i, \text { out }}^{\alpha}+v_{i, \text { int }}^{\alpha}
$$

where, $v_{i, \text { int }}^{\alpha}$ is the part of the range of $\alpha$-cut fuzzy number that intersects with any of the $\alpha$-cut fuzzy control limits, and $v_{i, i n}^{\alpha}$, $v_{i, \text { out }}^{\alpha}$ are the parts of the range of $\alpha$-cut fuzzy number that are between and out of the $\alpha$-cut control limits, respectively. Figure 1 represents an example of the definitions on triangular fuzzy numbers. For the first fuzzy number, (FN1), $v_{1, i n}^{\alpha}>0$, $v_{1, \text { out }}^{\alpha}=0$ and $v_{1, \text { int }}^{\alpha}>0$ and for the second one, (FN2), $v_{2, \text { in }}^{\alpha}=0, v_{2, \text { out }}^{\alpha}>0$ and $v_{2, \text { int }}^{\alpha}>0$. The membership function, which is the weighted sum of ranges, $v_{i, i n}^{\alpha}, v_{i, i n t}^{\alpha}$ and $v_{i, \text { out }}^{\alpha}$ is stated as follows:

$$
\mu_{i}=\frac{\gamma v_{i, i n t}^{\alpha}+(1-\gamma) v_{i, i n}^{\alpha}}{\gamma M_{i}^{\alpha}+(1-2 \gamma) L_{i}^{\alpha}}
$$

where $M_{i}^{\alpha}=\min \left\{\widetilde{U C L_{c}^{\alpha}}-\widetilde{L C} L_{a}^{\alpha}, v_{i}^{\alpha}\right\}$ and $L_{i}^{\alpha}=\min \left\{\left|\widetilde{U C L}_{a}^{\alpha}-L \widetilde{C} L_{c}^{\alpha}\right|, v_{i}^{\alpha}\right\}$ and are defined to standardize the membership function, and $\gamma$ 
is the weight of $\alpha$-cut fuzzy number that intersects with any one of the $\alpha$-cut control limits. Even though, the value of $\gamma$ is based on the production processes and expert's experiences, the value is expected to be in $[0,0.5]$, and so that $0<\gamma /(1-\gamma)<1$.

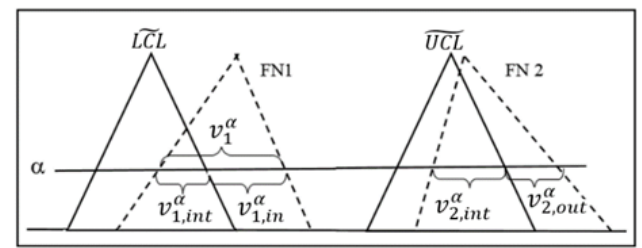

Fig. 1. Examples of $v_{i}^{\alpha}$ on triangular fuzzy numbers.

$\gamma$ is a random variable and has a probability distribution based on the process. This yields to have multiple values for membership degree of a fuzzy number which means fuzzy of fuzziness. Hence, the proposed fuzzy membership function necessitates the use of type-2 fuzzy set theory. Type-2 fuzzy sets, first introduced in [35] are the higher order of type-1 fuzzy sets. In type-1 fuzzy sets the membership degree for each element is a crisp number in $[0,1]$, whereas the membership degree of type- 2 fuzzy sets for each element is a fuzzy set in [0, 1]. For the simplicity of the approach and to increase the applicability, it is assumed that $\gamma$, which is determined by the decision maker(s), is a single constant value. This assumption reduces the procedure to type-1 fuzzy theory. After the calculation of membership degrees for each fuzzy number, the next step of the procedure is to describe the state of the process by the decision function given in (7) and monitoring the process.

$$
\text { Process }=\left\{\begin{array}{cc}
\text { in control, } & \text { if } \lambda<\mu_{i} \leq 1 \\
\text { out of control, } & \text { if } 0<\mu_{i} \leq \lambda
\end{array}\right.
$$

where, $\lambda$ is a parameter such that $0 \leq \lambda \leq 1$.

\section{B. Estimation of Decision Function Parameter}

The determination of the decision function parameter, $\lambda$ is an important part of the approach because if a value assigned is greater than it should be then the probability of type I error increases. This situation has the same effect with moving the control limits closer to the center line on Shewhart control charts. On the other hand, when the estimate is less than it should be, the probability of type I error decreases, and the probability of type II error increases. In this section, the estimation of the parameter is explained with the studies on membership degrees and their probability distributions. In the development process of the approach a detailed study is performed to estimate $\lambda$. Different data sets are experimented and fuzzy control charts are plotted under various process scenarios. Data sets from binomial, Poisson and normal distributions with a variety of parameter values are generated randomly for constructing fuzzy $p, n p, c, u, \bar{x}, R$ and $s$ control charts. Membership degrees of fuzzy numbers are calculated and the distribution of these membership degrees is investigated individually. Sixty one different continuous probability distributions are fitted to all data sets by EASYFIT
5.5. As a consequence of the applications, it is statistically proved that for all Shewart control charts, the distribution of membership degrees is beta distribution with two shape parameters which is left skewed with one peak. In order to standardize the estimates, all the data sets are considered together and the parameters are estimated by the maximum likelihood method which provides $\hat{\alpha}=3.6974$ and $\hat{\beta}=$ 1.1807. Figure 2 illustrates the histogram of a random sample of membership degrees of 1000 triangular fuzzy numbers which are randomly generated from different distributions. The membership degrees are calculated by the corresponding control charts.

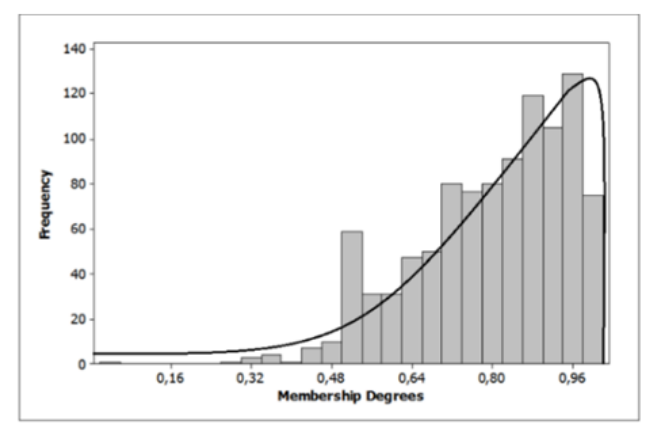

Fig. 2. Histogram of membership degrees and B (3.6974, 1.1807) $(\gamma=0.33$ and $\alpha=0.60)$.

The next step is to determine the value of the decision function parameter $\lambda$. It is estimated by the probability of observing a point outside the control limits when the process is in control, which is 0.0027 type I error probability of Shewhart control chart. The decision function for a fuzzy control chart is:

$$
\text { Process }=\left\{\begin{array}{cl}
\text { in control, } & \text { if } 0.1856<\mu_{i} \leq 1 \\
\text { out of control, } & \text { if } 0<\mu_{i} \leq 0.1856
\end{array}\right.
$$

\section{AN APPLICATION OF FUZZY C CONTROL CHART}

In this section, an application of the approach is presented by fuzzy c control chart. The number of defective products in each package is assumed to be expressed by fuzzy numbers. The defects or nonconformities occur according to Poisson distribution, which forms the basis of the c control chart. In order to plot a fuzzy control chart, a set of fuzzy data is generated randomly from the Poisson distribution. It is assumed that the process is in control when $c=25$ and triangular fuzzy numbers are formed by subtracting and adding 1.5 times of standard deviation of the data. A random sample of $30 \alpha$-cut triangular fuzzy numbers and membership degrees are given in Table I. Fuzzy control limits and fuzzy central line are illustrated in Figure 3 and obtained as follows: $\widetilde{L C L}=$ $(0.114,11.815,23.977), \widetilde{C L}=(18.317,27.567,36.817), \widetilde{U C L}=$ $(31.156,43.318,55.020)$ and $L \widetilde{C L}^{0.6}=[7.135,16.680], \widetilde{C L}^{0.6}=$ $[23.867,31.267], \widetilde{U C L}^{0.6}=[38.453,47.999]$. In this application, the membership degrees of fuzzy numbers are computed by the assumption that the importance of having a number between the fuzzy limits is twice the importance of intersecting with 
fuzzy limits, which means $\gamma=1 / 3$. Fuzzy c control chart is given in Figure 4. The membership degrees of 12 fuzzy numbers are 1 which means these numbers are completely between the $\alpha$-cut fuzzy control limits. The rest of the values are smaller than 1 , but not $\hat{\lambda}$. Consequently, the fuzzy c control chart shows a pattern in which $\alpha$-cut fuzzy numbers are randomly distributed and the process is in control.

TABLE I. SAMPLE $1: \alpha$-CUT TRIANGULAR FUZZY NUMBERS AND MEMBERSHIP DEGREES $(\alpha=0.6)$

\begin{tabular}{|c|c|c|c|c|c|c|c|c|c|}
\hline No & $\boldsymbol{a}_{\boldsymbol{i}}^{\boldsymbol{\alpha}}$ & $\boldsymbol{b}$ & $\boldsymbol{c}_{\boldsymbol{i}}^{\boldsymbol{\alpha}}$ & $\boldsymbol{\mu}_{\boldsymbol{i}}$ & $\mathbf{N o}$ & $\boldsymbol{a}_{\boldsymbol{i}}^{\boldsymbol{\alpha}}$ & $\boldsymbol{b}$ & $\boldsymbol{c}_{\boldsymbol{i}}^{\boldsymbol{\alpha}}$ & $\boldsymbol{\mu}_{\boldsymbol{i}}$ \\
\hline $\mathbf{1}$ & 14.30 & 18.00 & 21.70 & 0.8392 & $\mathbf{1 6}$ & 18.30 & 22.00 & 25.70 & 1.0000 \\
\hline $\mathbf{2}$ & 32.30 & 36.00 & 39.70 & 0.9158 & $\mathbf{1 7}$ & 39.30 & 43.00 & 46.70 & 0.5000 \\
\hline $\mathbf{3}$ & 14.30 & 18.00 & 21.70 & 0.8392 & $\mathbf{1 8}$ & 38.30 & 42.00 & 45.70 & 0.5104 \\
\hline $\mathbf{4}$ & 16.30 & 20.00 & 23.70 & 0.9743 & $\mathbf{1 9}$ & 27.30 & 31.00 & 34.70 & 1.0000 \\
\hline $\mathbf{5}$ & 10.30 & 14.00 & 17.70 & 0.5689 & $\mathbf{2 0}$ & 19.30 & 23.00 & 26.70 & 1.0000 \\
\hline $\mathbf{6}$ & 27.30 & 31.00 & 34.70 & 1.0000 & $\mathbf{2 1}$ & 16.30 & 20.00 & 23.70 & 0.9743 \\
\hline $\mathbf{7}$ & 32.30 & 36.00 & 39.70 & 0.9158 & $\mathbf{2 2}$ & 21.30 & 25.00 & 28.70 & 1.0000 \\
\hline $\mathbf{8}$ & 25.30 & 29.00 & 32.70 & 1.0000 & $\mathbf{2 3}$ & 10.30 & 14.00 & 17.70 & 0.5689 \\
\hline $\mathbf{9}$ & 32.30 & 36.00 & 39.70 & 0.9158 & $\mathbf{2 4}$ & 33.30 & 37.00 & 40.70 & 0.8482 \\
\hline $\mathbf{1 0}$ & 17.30 & 21.00 & 24.70 & 1.0000 & $\mathbf{2 5}$ & 38.30 & 42.00 & 45.70 & 0.5104 \\
\hline $\mathbf{1 1}$ & 21.30 & 25.00 & 28.70 & 1.0000 & $\mathbf{2 6}$ & 12.30 & 16.00 & 19.70 & 0.7040 \\
\hline $\mathbf{1 2}$ & 36.30 & 40.00 & 43.70 & 0.6455 & $\mathbf{2 7}$ & 18.30 & 22.00 & 25.70 & 1.0000 \\
\hline $\mathbf{1 3}$ & 19.30 & 23.00 & 26.70 & 1.0000 & $\mathbf{2 8}$ & 19.30 & 23.00 & 26.70 & 1.0000 \\
\hline $\mathbf{1 4}$ & 15.30 & 19.00 & 22.70 & 0.9068 & $\mathbf{2 9}$ & 33.30 & 37.00 & 40.70 & 0.8482 \\
\hline $\mathbf{1 5}$ & 19.30 & 23.00 & 26.70 & 1.0000 & $\mathbf{3 0}$ & 37.30 & 41.00 & 44.70 & 0.5779 \\
\hline
\end{tabular}

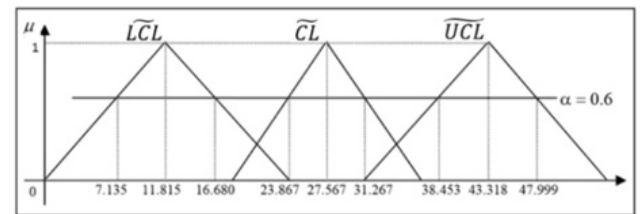

Fig. 3. Fuzzy control limits and central line.

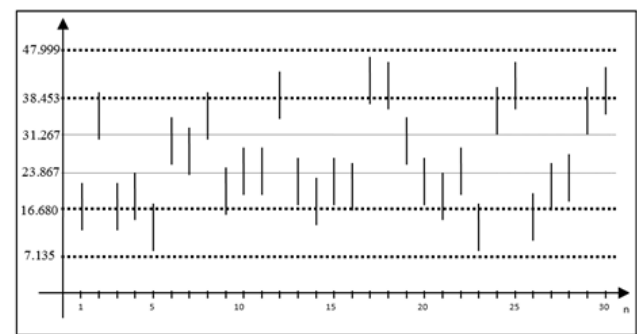

Fig. 4. Fuzzy c control chart for the data in Table I.

The application is repeated for the second data set generated from Poisson distribution with $c=27$. Thirty triangular fuzzy numbers are generated randomly for the second set and the membership degrees of these numbers are calculated. Table II presents $\alpha$-cut triangular fuzzy numbers and membership degrees of the second sample. Fuzzy c control chart in Figure 5 shows the $\alpha$-cut fuzzy control limits and the central line which are calculated by the first data set. The membership degrees of the corresponding fuzzy numbers that are smaller than $\hat{\lambda}$ are also presented on the chart. Figure 5 indicates that "the process is out of control". This result is due to the $48^{\text {th }}$ and $58^{\text {th }}$ fuzzy numbers which have membership values smaller than $\hat{\lambda}$. The 48th number is completely out of $\alpha$ cut fuzzy upper control limit with $\mu_{48}=0.000$. On the other hand, the $\alpha$-cut of the 58th fuzzy number intersects with the $\alpha$ cut fuzzy lower control limit with a membership degree of 0.1253 . Moreover, the pattern of the chart provides information about the randomness of the process. In Figure 5 there is a shift in the process mean up to 43th fuzzy number and then, a clear increasing trend. After the 48th number a descending trend can be observed. Consequently, all these symptoms and the membership degrees point toward the nonrandomness and out of control state in the process output.

TABLE II. SAMPLE $2: \alpha$-CUT TRIANGULAR FUZZY NUMBERS AND MEMBERSHIP DEGREES $(\alpha=0.6)$

\begin{tabular}{|c|c|c|c|c|c|c|c|c|c|}
\hline $\mathbf{N o}$ & $\mathbf{a}_{\mathbf{i}}^{\boldsymbol{\alpha}}$ & $\mathbf{b}$ & $\mathbf{c}_{\mathbf{i}}^{\boldsymbol{\alpha}}$ & $\boldsymbol{\mu}_{\mathbf{i}}$ & $\mathbf{N o}^{\mathbf{a}}$ & $\mathbf{a}_{\mathbf{i}}^{\boldsymbol{\alpha}}$ & $\mathbf{b}$ & $\mathbf{c}_{\mathbf{i}}^{\boldsymbol{\alpha}}$ & $\boldsymbol{\mu}_{\mathbf{i}}$ \\
\hline $\mathbf{3 1}$ & 18.84 & 23.00 & 27.16 & 1.0000 & $\mathbf{4 6}$ & 33.84 & 38.00 & 42.16 & 0.7812 \\
\hline $\mathbf{3 2}$ & 10.84 & 15.00 & 19.16 & 0.6540 & $\mathbf{4 7}$ & 31.84 & 36.00 & 40.16 & 0.9004 \\
\hline $\mathbf{3 3}$ & 24.84 & 29.00 & 33.16 & 1.0000 & $\mathbf{4 8}$ & 49.84 & 54.00 & 58.16 & 0.0000 \\
\hline $\mathbf{3 4}$ & 23.84 & 28.00 & 32.16 & 1.0000 & $\mathbf{4 9}$ & 44.84 & 49.00 & 53.16 & 0.1929 \\
\hline $\mathbf{3 5}$ & 7.84 & 12.00 & 16.16 & 0.5000 & $\mathbf{5 0}$ & 23.84 & 28.00 & 32.16 & 1.0000 \\
\hline $\mathbf{3 6}$ & 22.84 & 27.00 & 31.16 & 1.0000 & $\mathbf{5 1}$ & 24.84 & 29.00 & 33.16 & 1.0000 \\
\hline $\mathbf{3 7}$ & 14.84 & 19.00 & 23.16 & 0.8925 & $\mathbf{5 2}$ & 27.84 & 32.00 & 36.16 & 1.0000 \\
\hline $\mathbf{3 8}$ & 18.84 & 23.00 & 27.16 & 1.0000 & $\mathbf{5 3}$ & 28.84 & 33.00 & 37.16 & 1.0000 \\
\hline $\mathbf{3 9}$ & 21.84 & 26.00 & 30.16 & 1.0000 & $\mathbf{5 4}$ & 23.84 & 28.00 & 32.16 & 1.0000 \\
\hline $\mathbf{4 0}$ & 19.84 & 24.00 & 28.16 & 1.0000 & $\mathbf{5 5}$ & 24.84 & 29.00 & 33.16 & 1.0000 \\
\hline $\mathbf{4 1}$ & 20.84 & 25.00 & 29.16 & 1.0000 & $\mathbf{5 6}$ & 21.84 & 26.00 & 30.16 & 1.0000 \\
\hline $\mathbf{4 2}$ & 6.84 & 11.00 & 15.16 & 0.4830 & $\mathbf{5 7}$ & 15.84 & 20.00 & 24.16 & 0.9521 \\
\hline $\mathbf{4 3}$ & 27.84 & 32.00 & 36.16 & 1.0000 & $\mathbf{5 8}$ & 0.84 & 5.000 & 9.16 & 0.1253 \\
\hline $\mathbf{4 4}$ & 32.84 & 37.00 & 41.16 & 0.8408 & $\mathbf{5 9}$ & 5.84 & 10.00 & 14.16 & 0.4234 \\
\hline $\mathbf{4 5}$ & 23.84 & 28.00 & 32.16 & 1.0000 & $\mathbf{6 0}$ & 18.84 & 23.00 & 27.16 & 1.0000 \\
\hline
\end{tabular}

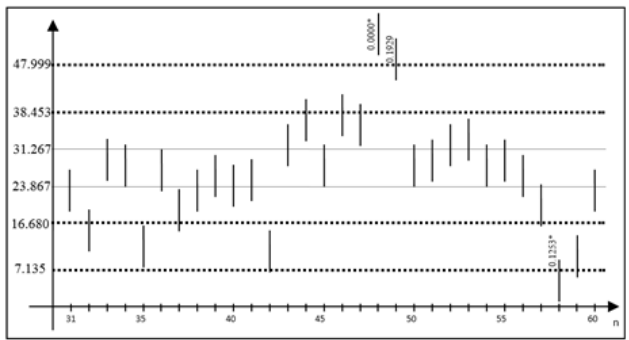

Fig. 5. Fuzzy c control chart for the data in Table II.

\section{FUZZY CONTROL CHART PERFORMANCE}

The most effective and commonly used performance measure is the average run length (ARL), which is the average number of points plotted on a control chart before an out of control condition is observed. If the process observations are uncorrelated, then ARL is calculated as given below

$$
\mathrm{ARL}=\frac{1}{p}=\frac{1}{P(\text { one point plots out of control })}
$$

If the process is in control, $\mathrm{ARL}$ is denoted by $\mathrm{ARL}_{0}$ where $\mathrm{ARL}_{0}=1 /$ (Type I error probability). It is desired to have a large value for $\mathrm{ARL}_{0}$ which gives fewer false alarm rates. On the other hand, if an assignable variable occurs, then the probability of being in the out of control state increases and more numbers give out of control signals. When the process is out of control, the ARL is denoted by $\mathrm{ARL}_{1}$ and defined by $A R L_{1}=1 /(1-$ Type II error probability $)$. In order to reduce the time to detect out of control situation, small values for $A R L_{1}$ 
are required. In this section, the performance of fuzzy c control chart is calculated and the fuzzy control chart is compared with Shewhart c control chart. All the computations are carried out by $\mathrm{C}++$ programming language and one million simulation runs are performed for each ARL. The fuzzy numbers are generated randomly, and it is assumed that the process is in control when the mean number of nonconformities is $c=c_{0}=$ 14 and the process is out of control when $c=c_{0}+\delta$ where $\delta=1,2, \ldots, 9$. Firstly, reference quantities of the fuzzy chart are determined to have the same $\mathrm{ARL}_{0}$ with Shewart control chart. These are $\alpha=0.6, \hat{\lambda}=0.1856$ and $\gamma=1 / 3$. Then, the process parameter is shifted and run lengths are averaged to get $\mathrm{ARL}_{1}$. Table III presents the summary of the results. The second column gives Shewart c control chart ARL values which are calculated by (12) and (13):

$$
\begin{aligned}
& \alpha=\mathrm{P}\{X<\mathrm{LCL} / c\}+\mathrm{P}\{X>\mathrm{UCL} / c\} \\
& \beta=\mathrm{P}\{\mathrm{LCL}<X<\mathrm{UCL} / c\}
\end{aligned}
$$

TABLE III. PERFORMANCE OF SHEWART AND FUZZY C CONTROL CHARTS

\begin{tabular}{|c|c|c|}
\hline Shift $(\boldsymbol{\delta})$ & ARL Shewhart c Control Chart & ARL Fuzzy c Control Chart \\
\hline $\mathbf{0}$ & 370.1580 & 374.6512 \\
\hline $\mathbf{1}$ & 160.6629 & 139.1889 \\
\hline $\mathbf{2}$ & 76.1332 & 69.5200 \\
\hline $\mathbf{3}$ & 39.6020 & 36.0776 \\
\hline $\mathbf{4}$ & 22.4160 & 21.4669 \\
\hline $\mathbf{5}$ & 13.6749 & 14.0383 \\
\hline $\mathbf{6}$ & 8.9138 & 9.4132 \\
\hline $\mathbf{7}$ & 6.1615 & 6.7849 \\
\hline $\mathbf{8}$ & 4.4863 & 5.2133 \\
\hline $\mathbf{9}$ & 3.4206 & 4.3388 \\
\hline
\end{tabular}

It can be concluded that for small shifts of the parameter, the fuzzy control chart $\mathrm{ARL}_{1}$ is significantly less than Shewart control chart $\mathrm{ARL}_{1}$, which means fuzzy control chart performance is better than Shewart control chart. As the shift increases the $\mathrm{ARL}_{1}$ values approach Shewart control chart and both of the charts result to almost the same performance.

\section{CONCLUSIONS AND DISCUSSION}

Many real life problems cannot be modeled or defined by classical methods. For this reason, fuzzy logic has been applied to real life applications and science. Fuzzy control charts that are constructed with fuzzy set theory reflect the uncertainty better than Shewhart control charts. This paper presents a fuzzy approach that integrates fuzzy set theory and the basics of Shewhart control charts. The approach is developed by a decision function and a membership function based on $\alpha$-cut fuzzy numbers, fuzzy $3 \sigma$ control limits, and intersection situations of fuzzy numbers and fuzzy control limits. An example is included to demonstrate the applicability and efficiency of the proposed fuzzy control charts. Moreover, the performance of fuzzy control charts is investigated and the fuzzy c control chart is compared with the Shewhart c control chart.
The approach is investigated with various applications in the development stage. The functions, parameters and decisions are tested for verification and validation of the approach. As a result of these studies, some advantages of the proposed approach are derived. At first, the type of fuzzy numbers is not specified. The choice of fuzzy numbers depends on the decision maker. Second, process is defined without using any transformation techniques, which minimizes the loss of information and biased decisions. The membership function is calculated by weighted mean of ratios. Third, with respect to the process the weights can be changed. The approach is easy to understand and calculate. It is flexible and does not require any important assumptions that restrict the application area. Therefore, the approach can be modified easily for different processes and applied to both variables and attributes control charts with small modifications. Another advantage of the approach is that the decision function has two linguistic decisions, "the process is in control" and "the process is out of control". Depending on the process, the number of decisions can be increased or a warning decision can be added. Finally, the process is defined by the membership function which provides more flexibility compared to Shewhart control charts and previous studies.

\section{REFERENCES}

[1] D. C. Montgomery, Introduction to Statistical Quality Control, 7th edition, John Wiley \& Sons Inc., NY, USA, 2013

[2] L. A. Zadeh, "Fuzzy sets", Information and Control, Vol. 8, No. 3, pp. 338-353, 1965

[3] T. Raz, J. H. Wang, "Probabilistic and memberships approaches in the construction of control charts for linguistic data", Production Planning \& Control, Vol. 1, No. 3, pp. 147-157, 1990

[4] J. H. Wang, T. Raz, "On the construction of control charts using linguistic variables", International Journal of Production Research, Vol. 28, No. 3, pp. 477-487, 1990

[5] A. Kanagawa, F. Tamaki, H. Ohta, "Control charts for process average and variability based on linguistic data", International Journal of Production Research, Vol. 31, No. 4, pp. 913-922, 1993

[6] H. Taleb, M. Limam, "On fuzzy and probabilistic control charts", International Journal of Production Research, Vol. 40, No. 12, pp. 28492863, 2002

[7] F. Franceschine, D. Romano, "Control chart for linguistic variables: a method based on the use of linguistic quantifiers", International Journal of Production Research, Vol. 37, No. 16, pp. 3791-3800, 1999

[8] M. Gulbay, C. Kahraman, D. Ruan, “ $\alpha$-Cuts fuzzy control charts for linguistic data", International Journal of Intelligent Systems, Vol. 19, No. 12, pp. 1173-1196, 2004

[9] K. Thaga, R. Sivasamy, "Control chart based on transition probability approach", Journal of Statistical and Econometric Methods, Vol. 4, No. 2, pp. 61-82, 2015

[10] J. H. Wang, C .H. Chen, "Economic statistical np-control chart designs based on fuzzy optimization", International Journal of Quality \& Reliability Management., Vol. 12, No. 1, pp. 88-92, 1995

[11] P. Grzegorzewski, O. Hryniewicz, "Soft methods in statistical quality control", Control Cybernet, Vol. 29, No. 1, pp. 119-140, 2000

[12] W. Woodall, K. L. Tsui, G. L. Tucker, "A review of statistical and fuzzy control charts based on categorical data", in: Frontiers in Statistical Quality Control, Vol. 5, pp. 83-89, Springer-Verlag, Berlin Heidelberg, 1997

[13] Y. K. Chen, C. Yeh, "An enhancement of DSI $\bar{X}$ control charts using a fuzzy genetic approach", The International Journal of Advanced Manufacturing Technology, Vol. 24, No. 1-2, pp. 32-40, 2004 
[14] C. B. Cheng, "Fuzzy process control: construction of control charts with fuzzy numbers", Fuzzy Sets and Systems, Vol. 154, No. 2, pp. 287-303, 2005

[15] M. Gulbay, C. Kahraman, "An alternative approach to fuzzy control charts: direct fuzzy approach”, Information Sciences, Vol. 77, No. 6, pp. 1463-1480, 2007

[16] O. Hryniewicz, "Statistics with fuzzy data in statistical quality control", Soft Computing, Vol. 12, No. 3, pp. 229-234, 2007

[17] M. H. Zavvar Sabegh, Z. Sabegha, A. Mirzazadeha, S. Salehiana, G. W. Weber, "A literature review on the fuzzy control chart; classifications \& analysis", International Journal of Supply and Operations Management, Vol. 1, No. 2, pp. 167-189, 2014

[18] D. J. Fonseca, M. E. Elam, L. Tibbs, "Fuzzy short-run control charts", Mathware \& Soft Computing, Vol. 14, pp. 81-101, 2007

[19] K. L. Hsieh, L. I. Tong, M. C. Wang, "The application of control chart for defects and defect clustering in IC manufacturing based on fuzzy theory", Expert Systems with Applications, Vol. 32, No. 3, pp. 765-776, 2007

[20] V. Amirzadeh, M. Mashinchi, A. Parchami, "Construction of p-charts using degree of nonconformity", Information Sciences, Vol. 179, No. 12, pp. 1501-1560, 2009

[21] M. H. Shu, H. C. Wu, "Monitoring imprecise fraction of nonconforming items using p control charts", Journal of Applied Statistics, Vol. 37, No. 8, pp. 1283-1297, 2010

[22] D. Wang, P. Li, M. Yasuda, "Construction of fuzzy control charts based on weighted possibilistic mean", Communications in Statistics - Theory and Methods, Vol. 43, No. 15, pp. 3186-3207, 2014

[23] M. H. Fazel Zarandi, I. B. Turksen, H. Kashan, "Fuzzy control charts for variable and attribute quality characteristic", Iranian Journal of Fuzzy Systems, Vol. 3, No. 1, pp. 31-44, 2006

[24] A. Faraz, M. B. Moghadam, "Fuzzy control chart a better alternative for Shewhart average chart", Quality \& Quantity, Vol. 41, No. 3, pp. 375385, 2007

[25] A. Faraz, R.B. Kazemzadeh, M. B. Moghadam, A. Bazdar, "Constructing a fuzzy Shewhart control chart for variables when uncertainty and randomness are combined", Quality \& Quantity, Vol. 44, No. 5, pp. 905-914, 2009

[26] A. Faraz, A. F. Shapiro, "An application of fuzzy random variables to control charts", Fuzzy Sets and Systems, Vol. 161, pp. 2684-2694, 2010

[27] M. H. Shu, H. C. Wu, "Fuzzy $\bar{X}$ and R control charts: Fuzzy dominance approach", Computers \& Industrial Engineering, Vol. 61, No. 3, pp. 676-686, 2011

[28] S. B. Akhundjanov, F. Pascual, "Moving range EWMA control charts for monitoring the Weibull shape parameter", Journal of Statistical Computation and Simulation, Vol. 85, No. 9, pp. 1864-1882, 2015

[29] J. D. T. Tannock, "A fuzzy control charting method for individuals", International Journal of Production Research, Vol. 41. No. 5, pp. 10171032, 2003

[30] M. Gulbay, C. Kahraman, "Development of fuzzy process control charts and fuzzy unnatural pattern analyses", Computational Statistics \& Data Analysis, Vol. 51, No. 1, pp. 434-451, 2006

[31] N. Pekin Alakoc, A. Apaydin, "Sensitizing rules for fuzzy control charts", World Academy of Science, Engineering and Technology, International Journal of Mechanical, Aerospace, Industrial, Mechatronic and Manufacturing Engineering, Vol. 7, No. 5, pp.931-935, 2013

[32] M. N. Pastuizaca Fernandez, A. Carrion Garcia, O. Ruiz Barzola, "Multivariate multinomial $\mathrm{T}^{2}$ control chart using fuzzy approach", International Journal of Production Research, Vol. 53, No. 7, pp. 22252238, 2015

[33] D. Wang, O. Hryniewicz, "A fuzzy nonparametric Shewhart chart based on the bootstrap approach", International Journal of Applied Mathematics and Computer Science, Vol. 25, No. 2, pp. 389-401, 2015

[34] B. Sadeghpour Gildeh, N. Shafiee, "X-MR control chart for autocorrelated fuzzy data using Dp,q-distance", The International Journal of Advanced Manufacturing Technology, Vol. 81, No. 5-8, pp. $1047-1054,2015$
[35] L. A. Zadeh, "The concept of a linguistic variable and its application to approximate reasoning - 1", Information Sciences, Vol. 8, No. 3, pp. $199-249,1975$

\section{AUTHORS PROFILE}

Nilufer Pekin Alakoc, graduated from the Department of Statistics at Middle East Technical University in Turkey and received her MSc degree from Industrial Engineering Department at the same University. She obtained her $\mathrm{PhD}$ degree in Statistics. Her research interests are mainly in the area of statistical quality control, statistical applications in industrial engineering and operations research. She is currently working as assistant professor at the American University of the Middle East in Kuwait.

Aysen Apaydin, is professor at the Department of Insurance and Actuary Sciences at Ankara University in Turkey. She has more than 35 years of experience in statistics and statistical applications. She has published 4 textbooks and more than 115 scientific publications and conference papers. She has worked in several administrative positions and served as organizer and council member of more than 20 congresses, symposiums and colloquiums. Dr. Apaydin is currently working as Student and Information Coordinator at Ankara University. 